\title{
A new method of endoscopic ultrasonography for determining lesion depth in early gastric cancer
}

This article was published in the following Dove Press journal:

Gastrointestinal Cancer:Targets and Therapy

28 December 201I

Number of times this article has been viewed

\author{
Atsushi Mitsunaga' \\ Tomoko Tagata' \\ Tetsuya Hamano' \\ Honami Teramoto' \\ Izumi Shirato² \\ Miho Shirato ${ }^{2}$ \\ Takayoshi Nishino ${ }^{2}$ \\ 'Department of Endoscopy, \\ ${ }^{2}$ Department of Gastroenterology, \\ Tokyo Women's Medical University \\ Yachiyo Medical Center, Yachiyo, \\ Chiba, Japan
}

Correspondence: Atsushi Mitsunaga Tokyo Women's Medical University Yachiyo Medical Center,

477-96 Owada-Shinden, Yachiyo,

Chiba 276-8524, Japan

Tel +8I 474506000

Fax +8I 474587047

Email mitunaga@tymc.twmu.ac.jp
Purpose: Endoscopic submucosal dissection (ESD) is recommended for the treatment of early gastric cancer (EGC) diagnosed as differentiated adenocarcinoma $<30 \mathrm{~mm}$ in diameter with depth of invasion into the submucosa $\leq 500 \mu \mathrm{m}$ (ie, submucosal [SM] 1 cancer). It is therefore important to develop a method for the differential diagnosis of SM1 (invasion depth $\leq 500 \mu \mathrm{m}$ ) from SM2/3 cancers (invasion depth $>500 \mu \mathrm{m}$ ), of which the latter cannot be treated with ESD. To aid in differential diagnosis, a prospective study was conducted to establish a new diagnostic method for more accurate differential diagnosis by measurement of lesion depth using endoscopic ultrasonography (EUS) as a preoperative diagnostic modality.

Patients and methods: The lesions of 92 EGC patients were examined by EUS prior to ESD or surgery to identify and measure the area with the most thickened submucosal layer. A pathological examination of the entire resected lesion was conducted to diagnose depth of invasion and histological type of EGC. Using receiver operating characteristic analysis, a cutoff threshold of $2.2 \mathrm{~mm}$ for submucosal thickness was calculated for differential diagnosis of mucosal (M)-SM1 from SM2/3 cancers.

Results: By using thickness of the submucosal layer as measured by EUS and a cut-off threshold of $2.2 \mathrm{~mm}$, M-SM1 could be distinguished from SM2/3 cancer with 98.6\% accuracy, 93.2\% sensitivity, and $94.7 \%$ specificity.

Conclusion: Using the thickness of the submucosal layer of an EGC lesion as determined by EUS and a cut-off threshold of $2.2 \mathrm{~mm}$ is a highly accurate means of differentiating M-SM1 from SM2/3 cancers when determining the best means of EGC treatment.

Keywords: adenocarcinoma, depth of invasion, early gastric cancer, endoscopic submucosal dissection, endoscopic ultrasonography, submucosal thickness

\section{Introduction}

Since endoscopic submucosal dissection (ESD) was first introduced as an alternative to endoscopic mucosal resectioning (EMR), the number of indications for endoscopic treatment of early gastric cancer (EGC) has been increasing. To clarify the indications for performing ESD for EGC, Gotoda et al examined the rates of lymph node metastases in patients who had undergone EGC. ${ }^{1}$ They reported that if the EGC pathology indicates a well-differentiated adenocarcinoma with diameter $<3 \mathrm{~cm}$ and depth of invasion into the submucosa $\leq 500 \mu \mathrm{m}$ (ie, a submucosal [SM] 1 cancer), ESD is indicated. It is important to differentiate mucosal (M)-SM1 (depth of invasion into the mucosa or submucosa, within $500 \mu \mathrm{m}$ ) from SM2/3 cancers, because in the case of $\mathrm{SM} 2 / 3$ cancers, the depth of invasion into the submucosa is $>500 \mu \mathrm{m}$ and thus these cancers cannot be treated with ESD. Therefore, differential diagnosis between M-SM1 
and SM2/3 cancers is extremely important in determining whether to use ESD as a treatment for EGC.

This diagnostic requirement calls for the development of a more accurate means of differential diagnosis of SM1 from SM2/3 cancers. Currently, the diagnostic accuracy of endoscopic ultrasound sonography (EUS), an objective method for the determination of lesion depth in EGC diagnosis, is not always very high (70\%-80\%). Another challenge the authors have recently reported is difficulty in measurement in cases where the lesion invades more than $500 \mu \mathrm{m}$ into the submucosal layer, where the thickness of the submucosal layer may increase to more than $2.0 \mathrm{~mm} .^{2}$ To address these challenges, a new diagnostic method was developed for more accurate differential diagnosis of M-SM1 and SM2/3 EGC lesions by using EUS as a preoperative diagnostic modality. By comparing the thickness of the submucosal layers of the EGC as measured by EUS and using a predetermined cut-off threshold of $2.2 \mathrm{~mm}$ for submucosal thickness in the diagnosis, M-SM1 cancers were able to be distinguished from SM2/3 with $98.6 \%$ accuracy, 93.2\% sensitivity, and $94.7 \%$ specificity.

\section{Materials and methods}

The study began with determination of differences in the thickness of the submucosal layer (sonographic layer 3) in each part of the stomach. To do so, EUS with instillation of nonaerated water was performed parallel to the normal mucosa of the lesser and greater curvature of the body and the antrum of ten healthy volunteers using a $20 \mathrm{MHz}$ miniature probe (UM-3R, Olympus, Tokyo, Japan); this was followed by measurement of the thickness of the entire stomach wall and the submucosal layer. Between January 2007 and August 2010, 97 consecutive patients ( 70 male, 27 female; mean age, 68.8 years) suspected of having EGC and with no indication of advanced cancer were prospectively enrolled into the study. Of the 97 patients, five were subsequently excluded, four of these due to the presence of cystic lesions in the submucosal layers and one due to muscularis propria invasion. After the patients had been diagnosed with EGC, mostly by routine endoscopic examination, EUS was performed to obtain images over a $3 \mathrm{~cm}$ range prior to performing either endoscopic or surgical treatment. Specifically, EUS was performed parallel to the mucosal surface of a lesion with the $20 \mathrm{MHz}$ miniature probe, with instillation of nonaerated water, using the same procedure to measure the submucosal thickness of the lesion as was used to measure the thickness of the submucosal layer in the healthy volunteers.

Using clear EUS images, the lesions were examined to identify the area with the thickest submucosal layer, and the thickness of this layer was measured using distance markers.
After the EUS images had been measured three times, the thickness of the thickest submucosal layer was recorded, and the data on the thickness of the submucosal layer obtained by EUS were compared with the data on the pathological depth of each EGC lesion. The lesions were treated either endoscopically or surgically according to the guidelines for the treatment of early gastric cancer proposed by the Japanese Gastric Cancer Association in 2004. ${ }^{3}$ A pathological examination of the entire resected lesion was conducted parallel to $2 \mathrm{~mm}$ thick sections by performing hematoxylin and eosin staining, after which the depth of invasion and histological type of EGC was diagnosed.

In these 92 cases, no invasion into the submucosal layer was observed and the lesion was therefore diagnosed as $\mathrm{M}$ cancer. In cases in which submucosal invasion was observed, the lesion was subclassified into one of three grades: SM1, if penetration into the submucosal layer was $<500 \mu \mathrm{m}$ from the muscularis mucosa; SM2, if penetration was $>500 \mu \mathrm{m}$ from the muscularis mucosa but did not reach the border of the muscularis propuria; or SM3, if penetration was sufficiently deep to reach the border of the muscularis propuria. The patients with M-SM1 and SM2/3 lesions were divided into either the $\mathrm{UL}(-)$ (without ulceration) group or UL(+) (with ulceration) group, according to the presence of ulceration, to examine the effect of ulceration on the submucosal thickness of the lesion and determine whether there was a significant difference in the submucosal thickness of the lesions of the two groups.

As the results of a preliminary examination ${ }^{2}$ had indicated that the submucosal thickness of the two groups followed a normal distribution, the M-SM1 and SM2/3 groups were evaluated by performing two-sample $t$-testing. Based on the results of this examination and receiver operating characteristic (ROC) analysis, a cut-off threshold of $2.2 \mathrm{~mm}$ for submucosal thickness was calculated for differential diagnosis of M-SM1 from SM2/3 cancers.

This study was performed in accordance with the ethical standards laid down in the 1964 Declaration of Helsinki. All persons or their families gave their written informed consent prior to their inclusion in the study.

\section{Technique for EUS}

The stomach was washed out with nonaerated water before scanning the lesion with EUS, in order to remove any tiny food particles and sputum. This eliminates most foreign matter in the instilled nonaerated water, ensuring that good EUS images are obtained. The stomach is then filled with instilled nonaerated water, and any tiny bubbles that may be present on the lesion are eliminated by flushing the endoscopic channel 
with the nonaerated water. Between scans, the EUS probe is kept parallel to and at a small distance from the mucosa. Once a good EUS image is seen, the image is frozen and captured, and the submucosal layer of the lesion is identified by comparison with the normal mucosa around it. Then, the thickness of the submucosal layer is determined on the image with the help of distance markers.

\section{Cases}

We examined the data of 92 cases (Table 1) and present the three typical cases below:

\section{Case I}

This was a typical case of M-SM1 cancer diagnosed using this method, for which ESD was performed. This patient presented with a slightly depressed lesion at the lesser curvature of the middle body with red-colored mucosa and a diameter of approximately $2.5 \mathrm{~cm}$ (Figure 1A). Based on the results of a biopsy, the lesion was diagnosed as a welldifferentiated IIc-type (superficial depressed type) adenocarcinoma, and the patient was thus diagnosed with EGC. After a routine endoscopic examination, EUS was performed with a $20 \mathrm{MHz}$ miniature probe, with instillation of nonaerated water, throughout the lesion, and the thickness of the most thickened submucosal layer was measured by freezing it three times (Figure 1B). After the thickness of the thickest submucosal layer of the lesion was determined to be $0.9 \mathrm{~mm}$, the lesion was diagnosed as an M-SM1 cancer. Since the lesion was diagnosed as a well-differentiated adenocarcinoma with a depth consistent with the diagnosis of M-SM1 and with a diameter $<3 \mathrm{~cm}$, ESD was performed. The entire lesion resected by ESD was pathologically classified as tub1 (welldifferentiated adenocarcinoma), SM1 (submucosal invasion of $252 \mu \mathrm{m}$ ), ly0 (no invasion into the lymph duct), v0 (no invasion into the venous duct), and cut-end (-) (the resected margin was negative for cancer) (Figure 1C).

\section{Case 2}

This was a typical case of SM2/3 cancer diagnosed using this method, for which surgical operation was performed. This patient presented with a IIc+III-type (superficial, mixed depressed, and excavated type) EGC at the greater curvature of the anglus. Based on the results of a biopsy, the lesion was diagnosed as a differentiated adenocarcinoma (Figure 2A). After performing a routine endoscopic examination, EUS was performed using a $20 \mathrm{MHz}$ miniature probe, with instillation of nonaerated water, throughout the lesion, and the thickness of the most thickened submucosal layer was measured by
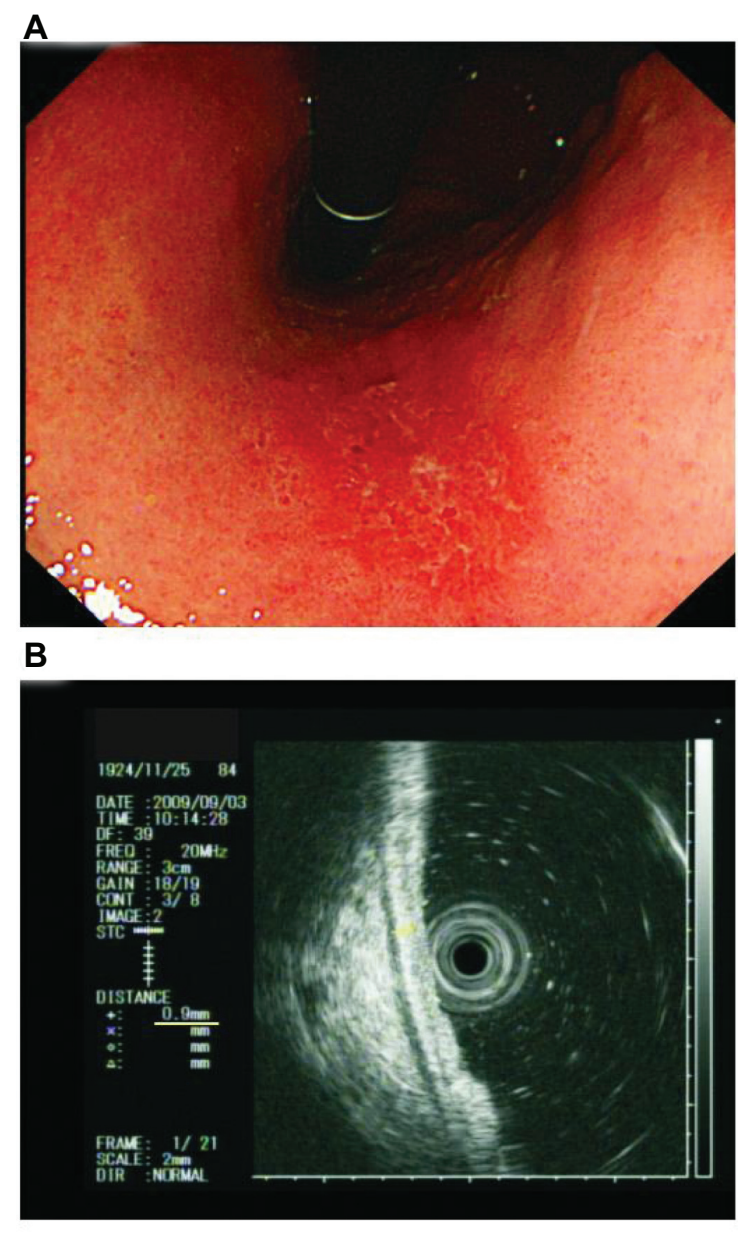

C

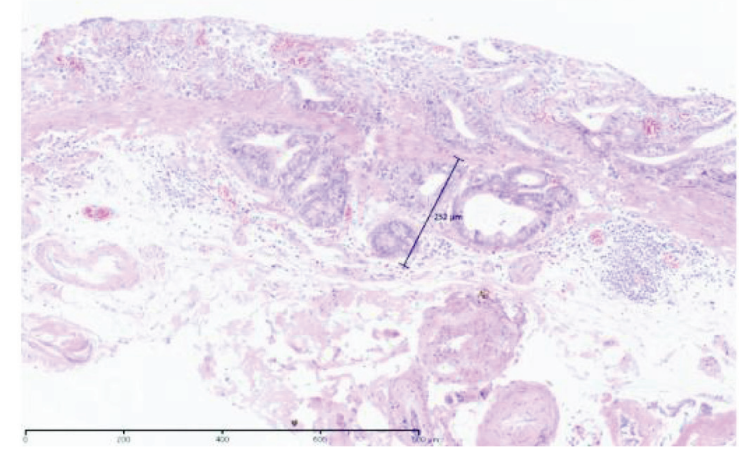

Figure I A slightly depressed lesion with red-colored mucosa at the lesser curvature of the middle body. (A) Endoscopic view. (B) The thickness of the most thickened submucosal layer of the lesion was measured as $0.9 \mathrm{~mm}$, and therefore mucosalsubmucosal (M-SM) I cancer was diagnosed. (C) The entire endoscopically resected lesion was pathologically classified as tubl (well-differentiated adenocarcinoma), SMI (submucosal invasion of $252 \mu \mathrm{m}$ ), ly0 (no invasion into the lymph duct), v0 (no invasion into the venous duct), and cut-end (-) (the resected margin was negative for cancer).

freezing it three times (Figure 2B). After the thickness of the thickest submucosal layer of the lesion was determined to be $3.2 \mathrm{~mm}$, the lesion was diagnosed as an SM2/3 cancer. As this diagnosis was a contraindication for ESD, the lesion was treated by surgical resectioning of the entire lesion. The entire resected lesion was pathologically classified as 
tub2 (moderately differentiated adenocarcinoma), SM3 (submucosal invasion of $3.48 \mathrm{~mm}$ ), ly1 (minimally invaded the lymph duct), v0, and cut-end (-) (Figure 2C).

\section{Case 3}

This was a typical case of M-SM1 cancer diagnosed using this method, even though the lesion was accompanied by severe
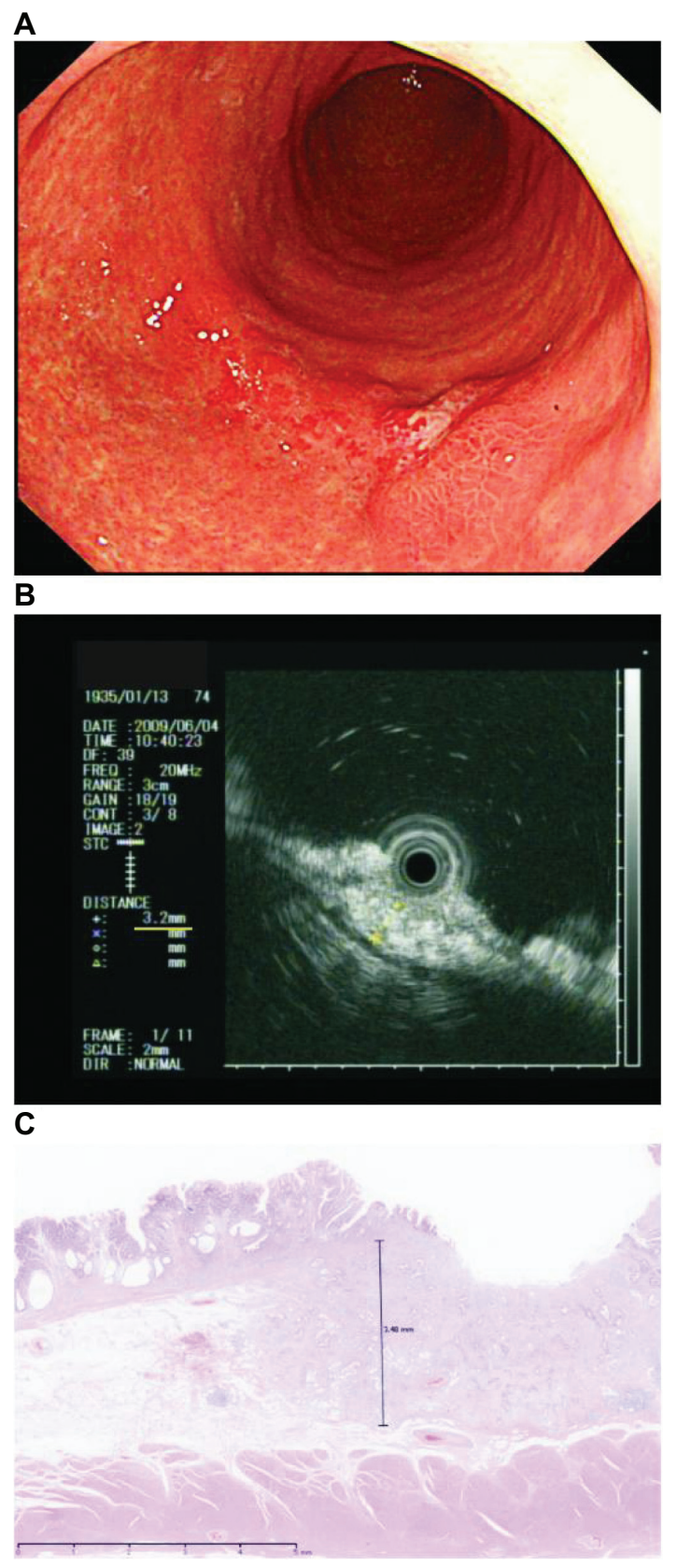

Figure 2 Ilc+III-type early gastric cancer at the greater curvature of the anglus. (A) Endoscopic view. (B) The thickness of the most thickened submucosal layer of the lesion was measured as $3.2 \mathrm{~mm}$, based on which submucosal (SM) 2/3 cancer was diagnosed. (C) The entire surgically resected lesion was pathologically classified as tub2 (moderately differentiated adenocarcinoma), SM3 (submucosal invasion of $3.48 \mathrm{~mm}$ ), lyl (minimally invaded the lymph duct), $\mathrm{v} 0$ (no invasion into the venous duct), and cut-end $(-)$ (the resected margin was negative for cancer). fibrosis caused by ulceration. This patient presented with a IIc+III-type EGC lesion at the anterior wall of the lower body that was diagnosed as an undifferentiated adenocarcinoma based on a biopsy evaluation (Figure 3A). After performing a routine endoscopic examination, EUS was performed with a $20 \mathrm{MHz}$ miniature probe, with instillation of nonaerated water, throughout the lesion, and the thickness of the most thickened

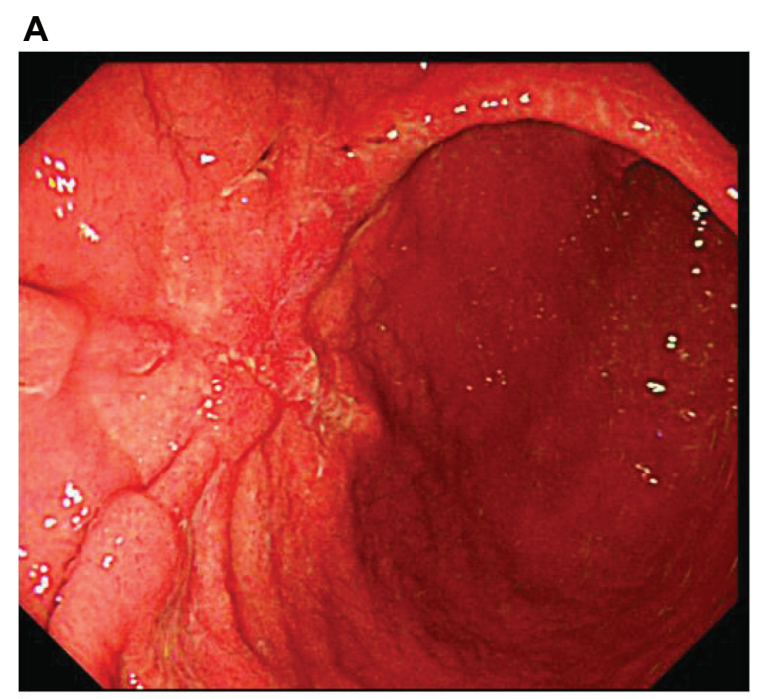

B

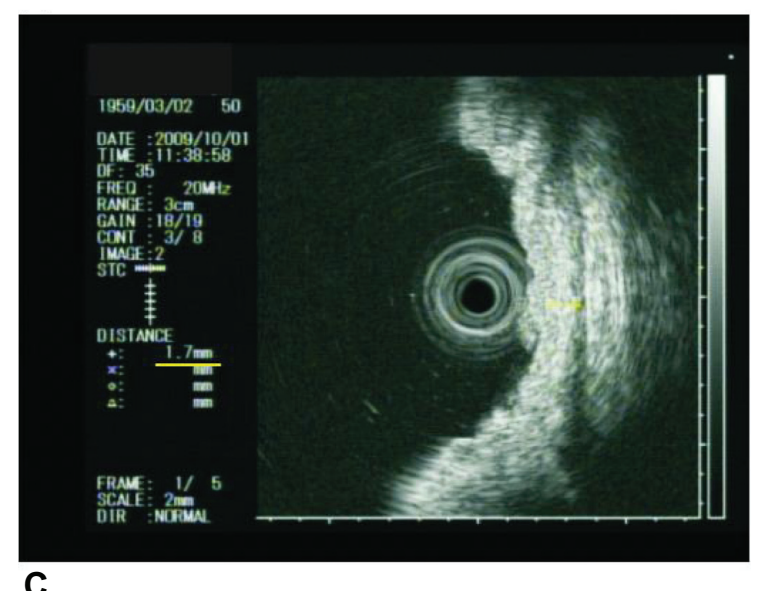

C

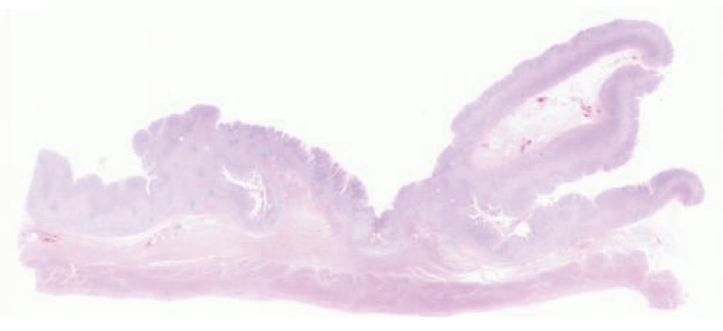

Figure 3 Ilc+lll-type early gastric cancer at the anterior wall of the lower body. (A) Endoscopic view. (B) The thickness of the most thickened submucosal layer of the lesion was measured as $1.7 \mathrm{~mm}$, based on which M-SMI cancer was diagnosed. (C) The entire surgically resected lesion was pathologically classified as por (poorly differentiated adenocarcinoma), mucosal, ly0 (no invasion into the lymph duct), v0 (no invasion into the venous duct), and cut-end (-) (the resected margin was negative for cancer). 
submucosal layer was measured by freezing it three times (Figure 3B). After the thickness of the thickest submucosal layer of the lesion was determined to be $1.7 \mathrm{~mm}$, the lesion was diagnosed as an M-SM1 cancer. Despite being an M-SM1 cancer, the pathology of the lesion was a contraindication for ESD, and the lesion was therefore surgically resected. The entire resected lesion was pathologically classified as por (poorly differentiated adenocarcinoma), M, ly0, v0, and cut-end (-) (Figure 3C). Although advanced fibrosis was observed in the submucosal layer at the center of the lesion, no thickening of the submucosal layer was observed.

\section{Results}

ESD and surgery was performed for an equal number (46) of the 92 patients (1I, 17IIa, 14IIa+IIc, 4IIb, 37IIc, 14IIc+III, and 5III+IIc) (for detailed information on each lesion, refer to Table 1). A significant difference was observed between the thickness of the entire stomach wall in the body and the antrum (body, $2.46 \pm 0.58 \mathrm{~mm}$; antrum, $3.15 \pm 1.15 \mathrm{~mm}$ ), but no significant difference in thickness was observed between the submucosal layer (body, $0.70 \pm 0.18 \mathrm{~mm}$; antrum, $0.64 \pm 0.20 \mathrm{~mm}$ ). The types of EGC lesions are shown in Table 1, and the distribution in the stomach of each lesion with or without ulceration is shown in Table 2. Based on analysis of the pathological depth of the lesion, 49 M cancers, 22 SM1 cancers, ten SM2 cancers, and eleven SM3 cancers were diagnosed (Figure 4). The thickest submucosal layer, as determined by EUS, was $1.29 \pm 0.46 \mathrm{~mm}$ in the M cancers, $1.61 \pm 0.47 \mathrm{~mm}$ in the SM1 cancers, $2.89 \pm 0.97 \mathrm{~mm}$ in the SM2 cancers, and $3.34 \pm 0.77 \mathrm{~mm}$ in the SM3 cancers (Figure 5). Significant differences were observed in the submucosal thickness of the M-SM1 cancers $(1.39 \pm 0.49 \mathrm{~mm})$ compared to the SM2/3 cancers ( $3.00 \pm 0.92 \mathrm{~mm} ; P<0.001$; Figure 6$)$. When the M-SM1 cancers were subdivided into the UL(-) group and UL(+) groups and the differences in the submucosal thickness of each group were examined (Figure 7), no significant differences were observed $(P=0.469)$. It was not possible to perform the same comparison for the SM2/3 cancers because only two cases had been diagnosed as UL(-). Using the previously determined cutoff threshold of $2.2 \mathrm{~mm}$ for submucosal thickness in the differential diagnosis of M-SM1 from SM2/3 cancers, it was possible to distinguish M-SM1 from SM2/3 cancers with $98.6 \%$ accuracy, 93.2\% sensitivity, and 94.7\% specificity (Figure 8 ).

\section{Discussion}

Currently, ESD is extensively performed for the treatment of patients with EGC. It was initially introduced as an alternative to EMR, but is gaining popularity as the treatment for EGC. If the depth of the lesion is consistent with a diagnosis of SM1 and its diameter is $<3 \mathrm{~cm}$, ESD rather than EMR is often indicated for treatment. Under these circumstances, it is extremely important to perform a precise differential diagnosis of the depth of the EGC lesion before initiating therapy. Several medical institutions use a two-step procedure to determine the necessity of an additional surgical operation after pathological diagnosis based on the depth of the ESD specimen. However, as this procedure is complex and resource intensive, it is desirable to determine whether ESD is clearly indicated by making a correct diagnosis based on the depth of the lesion. At present, EUS is considered the most objective means of determining lesion depth, ${ }^{4-6}$ but its diagnostic accuracy is not always very high. ${ }^{7-9}$

As a means of addressing this challenge, the efficacy of using the indicator of submucosal thickness of a lesion was examined in this study as a means of improving the accuracy of diagnosis. The authors have previously reported that the thickness of the submucosal layer increases according to the degree of invasion of cancer into the submucosa. ${ }^{2}$ Based on these findings, it was hypothesized that increases in the thickness of the submucosal layer are primarily caused by the infiltration of cancerous and inflammatory cells. ${ }^{10}$ If the lesion has invaded more than $500 \mu \mathrm{m}$ into the submucosal layer and, therefore, been diagnosed as an SM2/3 cancer, the submucosal layer is expected to be extremely thick. We thus further hypothesized that using the thickness of the submucosal layer as an indicator in the differential diagnosis of M-SM1 from SM2/3 cancers may allow for highly accurate diagnosis.

Although the absolute value of the submucosal thickness is often discussed as an indicator, this variable may depend on the section of the stomach that is examined. To examine this possibility, EUS of normal mucosa was performed at the lesser and greater curvature of the body and the antrum with instillation of nonaerated water. While doing so, a significant difference was observed between the thickness of the entire stomach wall in the body and the antrum, but no significant difference in thickness of the submucosal layer. Therefore, the possibility that the localization of a lesion could influence the thickness of the submucosal layer was dismissed. In addition, it was recognized that this concern could be resolved by comparing the ratio of the submucosal thickness in the lesion with the surrounding normal mucosa that had been already examined in the resected specimen. ${ }^{2}$ Having concluded that submucosal thickness does not vary according to the stomach section, it could further be concluded that using the absolute 
Table I Patient sex and age and characteristics of the lesions

\begin{tabular}{|c|c|c|c|c|c|c|c|c|}
\hline $\begin{array}{l}\text { Sex (malel } \\
\text { female) }\end{array}$ & Age (y) & Shape & Location & $\begin{array}{l}\text { Submucosal } \\
\text { thickness }(\mathrm{mm})\end{array}$ & $\begin{array}{l}\text { EUS } \\
\text { diagnosis }\end{array}$ & $\begin{array}{l}\text { Treatment } \\
\text { course }\end{array}$ & Pathology & $\begin{array}{l}\text { Pathological } \\
\text { depth }\end{array}$ \\
\hline$M$ & 48 & III+Ilc & Angulus lesser & 1.5 & M-SMI & Surgery & por & SMI \\
\hline$M$ & 63 & Ilc & Cardia lesser & 0.9 & M-SMI & ESD & tubl & M \\
\hline$M$ & 54 & Ilc & Angulus posterior & 1.5 & M-SMI & Surgery & tub2 & $M$ \\
\hline M & 76 & $\|c+\| I \|$ & Angulus posterior & 4.7 & $\mathrm{SM} 2 / 3$ & Surgery & tub2 & SM2 \\
\hline$M$ & 66 & Ilc & Middle body greater & 2.3 & $\mathrm{SM} 2 / 3$ & Surgery & sig & SM2 \\
\hline M & 80 & Ilc & Antrum greater & 1.2 & M-SMI & ESD & tubl & M \\
\hline$M$ & 56 & Illb & Middle body posterior & $\mathrm{I} .4$ & M-SMI & Surgery & tub2 & M \\
\hline $\mathrm{F}$ & 69 & Ilc & Lower body anterior & 0.9 & M-SMI & ESD & porl & $M$ \\
\hline M & 65 & Ilc & Antrum greater & 1.2 & M-SMI & ESD & tub2 & $M$ \\
\hline M & 54 & Ila+llc & Cardia lesser & 1.2 & M-SMI & ESD & tubl & $M$ \\
\hline$M$ & 66 & Ila & Upper body lesser & 1.8 & M-SMI & Surgery & tubl/2 & $M$ \\
\hline M & 36 & Ilc & Lower body anterior & 0.9 & M-SMI & Surgery & porl & M \\
\hline$M$ & 56 & Ila+llc & Upper body anterior & 4.1 & $\mathrm{SM} 2 / 3$ & Surgery & muc & SM2 \\
\hline M & 62 & III+IIc & Lower body anterior & 0.9 & M-SMI & Surgery & tub2 & M \\
\hline M & 72 & Ilc & Antrum posterior & 0.9 & M-SMI & ESD & tubl & $M$ \\
\hline M & 64 & Ilc & Angulus greater & $\mathrm{I} .4$ & M-SMI & Surgery & sig & M \\
\hline M & 65 & $\| \mathrm{Il}+\mathrm{III}$ & Lower body posterior & 1.9 & M-SMI & Surgery & sig & SM2 \\
\hline $\mathrm{F}$ & 74 & Ilc & Upper body greater & 3.5 & $\mathrm{SM} 2 / 3$ & Surgery & por2 & SM2 \\
\hline M & 80 & Ilc & Lower body lesser & $\mathrm{I} .4$ & M-SMI & Surgery & tub2 & M \\
\hline M & 74 & $\| c+I I I$ & Antrum anterior & 1.2 & M-SMI & ESD & tubl/2 & SMI \\
\hline M & 86 & Ila & Angulus lesser & 1.6 & M-SMI & ESD & tubl/2 & M \\
\hline $\mathrm{F}$ & 58 & Ilc & Middle body anterior & 2.2 & $\mathrm{SM} 2 / 3$ & Surgery & sig & SMI \\
\hline M & 65 & $\| \mathrm{Il}+\mathrm{III}$ & Upper body posterior & 1.6 & M-SMI & Surgery & tub2/por & SMI \\
\hline M & 67 & Ilc advanced & Middle body lesser & 2.3 & $\mathrm{SM} 2 / 3$ & Surgery & porl & SM2 \\
\hline $\mathrm{F}$ & 77 & Ilc & Prepylorus lesser & 3.5 & $\mathrm{SM} 2 / 3$ & ESD & tubl & M \\
\hline $\mathrm{F}$ & 64 & $\mathrm{Ilc}+\mathrm{I}$ & Antrum anterior & 4.7 & $\mathrm{SM} 2 / 3$ & Surgery & muc & SM3 \\
\hline M & 77 & Ilc & Middle body greater & 1.2 & M-SMI & ESD & tubl & SMI \\
\hline M & 76 & Ila & Lower body lesser & 0.7 & M-SMI & ESD & tubl & M \\
\hline$F$ & 65 & Ila+llc & Middle body lesser & 2.5 & $\mathrm{SM} 2 / 3$ & Surgery & por & SM3 \\
\hline M & 67 & Ilc advanced & Angulus anterior & 3 & $\mathrm{SM} 2 / 3$ & Surgery & por & SM3 \\
\hline$F$ & 47 & Ilc & Antrum greater & 4.2 & $\mathrm{SM} 2 / 3$ & Surgery & por & SM3 \\
\hline $\mathrm{F}$ & 72 & Ila+llc & Angulus lesser & 0.9 & M-SMI & ESD & tubl & M \\
\hline M & 77 & Ila & Cardia anterior & 1.2 & M-SMI & Surgery & pap & SMI \\
\hline$F$ & 66 & III+Ilc & Middle body greater & 1.9 & M-SMI & Surgery & por & SM2 \\
\hline $\mathrm{F}$ & 77 & III+Ilc & Upper body lesser & 0.7 & M-SMI & Surgery & tubl/2 & M \\
\hline $\mathrm{F}$ & 67 & $\mathrm{llb}$ & Angulus greater & 1.9 & M-SMI & ESD & por & M \\
\hline $\mathrm{F}$ & 70 & Ilc & Middle body lesser & 0.7 & M-SMI & ESD & tubl & $M$ \\
\hline$M$ & 71 & Ilb & Upper body anterior & 1.3 & M-SMI & Surgery & tub2/por & $M$ \\
\hline$M$ & 65 & Ilc & Middle body anterior & 1.9 & M-SMI & ESD & tub2 & SMI \\
\hline$M$ & 74 & $\| \mathrm{l}+\mathrm{III}$ & Angulus greater & 3.3 & $\mathrm{SM} 2 / 3$ & Surgery & tub2 & SM3 \\
\hline $\mathrm{F}$ & 62 & Ilc & Angulus greater & I & M-SMI & ESD & sig & $M$ \\
\hline $\mathrm{F}$ & 63 & $\| c+I I I$ & Angulus posterior & 2.5 & $\mathrm{SM} 2 / 3$ & Surgery & por & M \\
\hline M & 67 & $\| \mathrm{Il}+\mathrm{III}$ & Antrum posterior & 2.4 & $\mathrm{SM} 2 / 3$ & Surgery & por/sig & M \\
\hline$M$ & 71 & Ila & Antrum lesser & 0.5 & M-SMI & ESD & tubl/2 & M \\
\hline$M$ & 69 & Ilc & Upper body anterior & 1.5 & M-SMI & ESD & tub2 & SMI \\
\hline M & 72 & Ilc & Angulus greater & $\mathrm{I}$ & M-SMI & ESD & tub2 & M \\
\hline M & 58 & Ilc & Angulus lesser & 1.6 & M-SMI & Surgery & Por/sig & SMI \\
\hline$M$ & 73 & lla & Upper body lesser & 1.8 & M-SMI & ESD & tub2-por & M \\
\hline$F$ & 73 & lla & Middle body posterior & 2.1 & M-SMI & Surgery & muc & SMI \\
\hline$M$ & 84 & Ilc & Upper body lesser & 0.9 & M-SMI & ESD & tubl & SMI \\
\hline$F$ & 69 & III+Ilc & Angulus posterior & 2.8 & $\mathrm{SM} 2 / 3$ & Surgery & tub2 & SM3 \\
\hline $\mathrm{F}$ & 50 & Ilc & Angulus anterior & 1.7 & M-SMI & Surgery & por/sig & $M$ \\
\hline $\mathrm{F}$ & 87 & Ila & Angulus lesser & $\mathrm{I} .4$ & M-SMI & Surgery & tub2 & $M$ \\
\hline$M$ & 48 & Ila+llc & Upper body lesser & 0.8 & M-SMI & ESD & tub2/por & $M$ \\
\hline
\end{tabular}


Table I (Continued)

\begin{tabular}{|c|c|c|c|c|c|c|c|c|}
\hline $\begin{array}{l}\text { Sex (male/ } \\
\text { female) }\end{array}$ & Age (y) & Shape & Location & $\begin{array}{l}\text { Submucosal } \\
\text { thickness (mm) }\end{array}$ & $\begin{array}{l}\text { EUS } \\
\text { diagnosis }\end{array}$ & $\begin{array}{l}\text { Treatment } \\
\text { course }\end{array}$ & Pathology & $\begin{array}{l}\text { Pathological } \\
\text { depth }\end{array}$ \\
\hline M & 86 & $\mathrm{Ila}+\mathrm{Ilc}$ & Antrum lesser & 3.1 & $\mathrm{SM} 2 / 3$ & Surgery & tub2/por & SM3 \\
\hline M & 84 & Ilc & Upper body lesser & 0.8 & M-SMI & ESD & tubl & SMI \\
\hline$M$ & 61 & Ilc & Antrum anterior & 0.8 & M-SMI & ESD & por/sig & M \\
\hline M & 59 & Ilc & Angulus greater & 3.1 & $\mathrm{SM} 2 / 3$ & Surgery & tub2 & SM3 \\
\hline M & 48 & Ila+Ilc & Lower body posterior & 2.9 & $\mathrm{SM} 2 / 3$ & Surgery & tub2/por & SM2 \\
\hline M & 69 & Ilc+III & Antrum anterior & 1.3 & M-SMI & ESD & tub2 & M \\
\hline $\mathrm{F}$ & 75 & Ila & Lower body anterior & $\mathrm{I} .4$ & M-SMI & ESD & tubl & $M$ \\
\hline M & 67 & IIc+III & Antrum greater & 1.8 & M-SMI & Surgery & muc & SMI \\
\hline M & 67 & $\mathrm{Ila}+\mathrm{Ilc}$ & Antrum anterior & 2.2 & $\mathrm{SM} 2 / 3$ & Surgery & tub2/por & SMI \\
\hline$F$ & 73 & $\| \mathrm{Il}+\mathrm{III}$ & Angulus lesser & 1 & M-SMI & ESD & tub2 & M \\
\hline$M$ & 73 & Ila+llc & Cardia lesser & 0.9 & M-SMI & ESD & tubl & $M$ \\
\hline$M$ & 74 & Ila & Antrum greater & 0.9 & M-SMI & ESD & pap & $M$ \\
\hline$M$ & 89 & Ila & Middle body lesser & 1.7 & M-SMI & ESD & tubl & SMI \\
\hline M & 61 & $\mathrm{Ila}+\mathrm{Ilc}$ & Angulus anterior & 2.3 & $\mathrm{SM} 2 / 3$ & Surgery & tubl & SMI \\
\hline M & 74 & $\mathrm{Ila}+\mathrm{Ilc}$ & Lower body lesser & 0.8 & M-SMI & ESD & tubl & M \\
\hline$M$ & 69 & Ila+llc & Angulus lesser & 1.8 & M-SMI & Surgery & por & SMI \\
\hline $\mathrm{F}$ & 86 & Ila & Angulus anterior & 1.8 & M-SMI & ESD & tubl & $M$ \\
\hline$M$ & 67 & IIc+III & Lower body lesser & 1.2 & M-SMI & ESD & tubl & $M$ \\
\hline M & 72 & I & Fornix greater & 1.6 & M-SMI & ESD & tub2 & SMI \\
\hline$F$ & 69 & Ilc & Middle body posterior & 3.4 & $\mathrm{SM} 2 / 3$ & Surgery & por & SM3 \\
\hline M & 77 & Ila & Middle body lesser & 1.2 & M-SMI & ESD & pap & M \\
\hline M & 58 & $\mathrm{Ila}+\mathrm{Ilc}$ & Upper body posterior & 2.7 & $\mathrm{SM} 2 / 3$ & Surgery & tubl & SM3 \\
\hline M & 69 & Ila & Upper body lesser & 2 & M-SMI & ESD & tubl & $M$ \\
\hline $\mathrm{F}$ & 85 & lla & Middle body lesser & 1.1 & M-SMI & ESD & pap & M \\
\hline M & 68 & Ila & Angulus posterior & 2.6 & $\mathrm{SM} 2 / 3$ & Surgery & tubl & SMI \\
\hline M & 74 & Ilc & Angulus lesser & 0.9 & M-SMI & ESD & tub2 & M \\
\hline M & 74 & $\| \mathrm{Il}+\mathrm{II}$ & Antrum greater & 1.2 & M-SMI & ESD & tub2 & SMI \\
\hline$F$ & 75 & Ilc & Antrum greater & 1.7 & M-SMI & ESD & tub2 & SMI \\
\hline M & 60 & Ilc & Antrum lesser & 1.5 & M-SMI & ESD & tubl & M \\
\hline$M$ & 76 & Ilc & Antrum lesser & 3.6 & $\mathrm{SM} 2 / 3$ & Surgery & por & SM3 \\
\hline M & 67 & Ilc & Lower body anterior & 1.9 & M-SMI & ESD & tub2 & SM2 \\
\hline $\mathrm{F}$ & 66 & Ilc & Lower body posterior & 0.9 & M-SMI & Surgery & tub2 & SMI \\
\hline $\mathrm{F}$ & 61 & $\mathrm{Ila}+\mathrm{Ilc}$ & Angulus posterior & 1.9 & M-SMI & Surgery & por & M \\
\hline M & 70 & $\| \mathrm{Il}+\mathrm{III}$ & Prepylorus lesser & 2 & M-SMI & Surgery & tub2 & $M$ \\
\hline M & 78 & Ilc & Upper body posterior & 1.5 & M-SMI & ESD & tubl & $M$ \\
\hline$F$ & 76 & Ilb & Angulus lesser & 1.2 & M-SMI & Surgery & por & M \\
\hline M & 74 & Ila & Lower body lesser & 1.6 & M-SMI & ESD & tubl & M \\
\hline$M$ & 82 & Ilc+III & Lower body lesser & 1.8 & M-SMI & ESD & tubl & SM2 \\
\hline
\end{tabular}

Abbreviations: M, mucosal; SM, submucosal; ESD, endoscopic submucosal dissection; tubl, well-differentiated adenocarcinoma; tub2, moderately differentiated adenocarcinoma; ly0, no invasion into the lymph duct; lyl, minimally invaded the lymph duct; v0, no invasion into the venous duct; cut-end (-), the resected margin was negative for cancer; sig, signet ring cell carcinoma; muc, mucinous adenocarcinoma; pap, papillotubular adenocarcinoma.

values of the submucosal thickness would not affect the accuracy of the results. Thereafter, the absolute value of the submucosal thickness was examined for real-time diagnosis of invasion depth by EUS. As Yasuda ${ }^{11}$ had proposed that the resolution of the $20 \mathrm{MHz}$ miniature probe used in this study should be $0.08 \mathrm{~mm}$, this instrument was considered appropriate for this study, as well as appropriate for comparing the thickness of the submucosal layer with a $0.1 \mathrm{~mm}$ scale.

As the previous method used for diagnosing the depth of EGC by EUS depended on deciphering the EUS figures, it was a relatively subjective method, and therefore prone to human error. ${ }^{12,13}$ The reported accuracy of this method is only $70 \%-80 \%,{ }^{14-16}$ although it was reported to be higher by Mouri et al. ${ }^{17}$ Nevertheless, as the accuracy of the diagnosis can differ across operators, it is an inadequate means of diagnosing the depth of EGC lesions prior to treatment. In undifferentiated adenocarcinomas in particular, the accuracy of EGC depth diagnosis tends to be low $^{18}$ because it is often difficult to define EUS figures in such cancers at the margin of submucosal invasion, which affects the accuracy 
Table 2 The presence or absence of ulceration and the depth and distribution of invasion in the stomach of each EGC patient

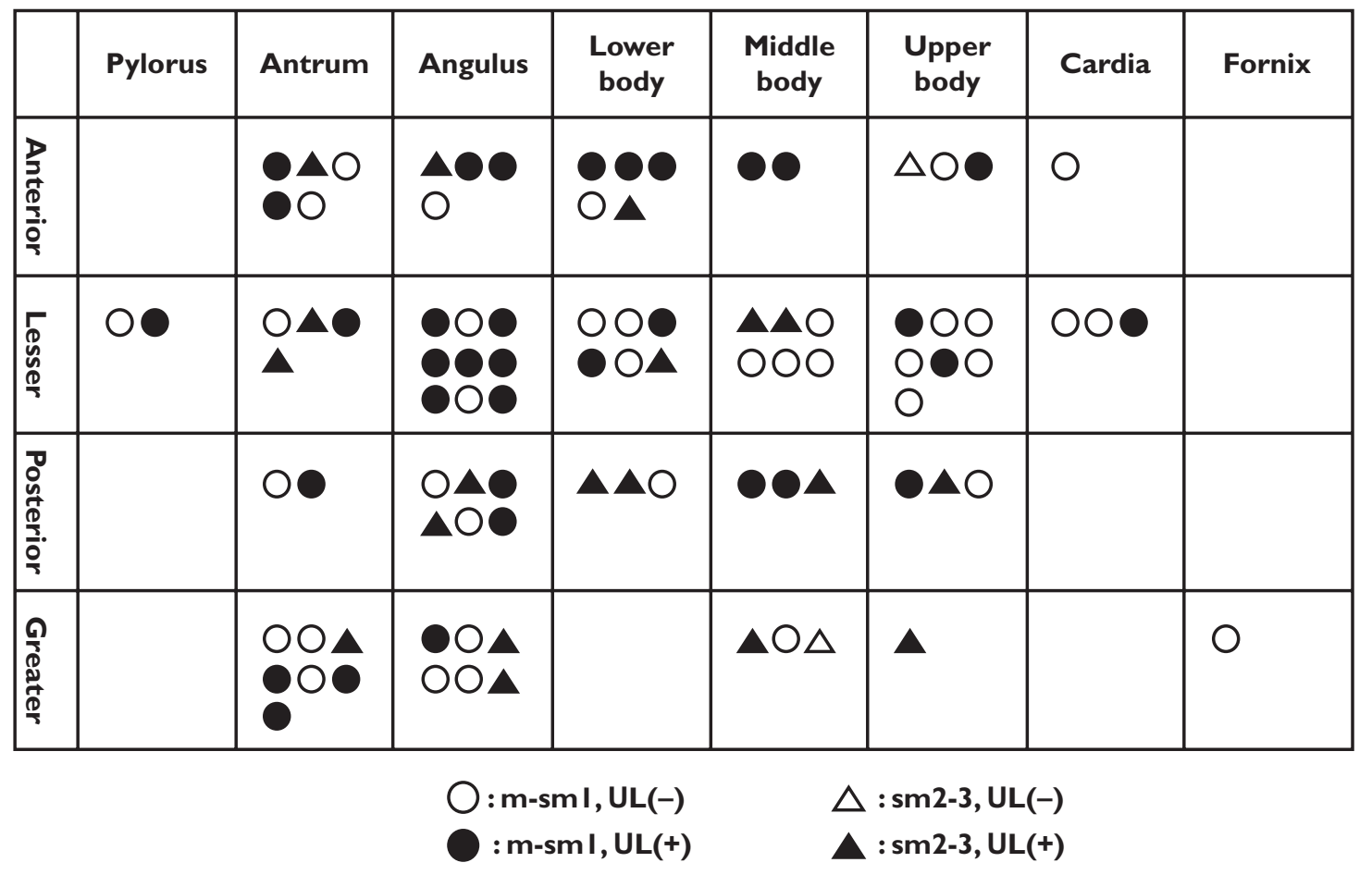

Notes: $\mathrm{n}=92$.

Abbreviations: M, mucosal; SM, submucosal; UL(-), without ulceration; UL(+), with ulceration.

of the diagnosis. The authors' method, in contrast, measures only the thickness of the submucosal layer by EUS, therefore, it is not affected by the quality of EUS images, greatly contributing to the diagnostic accuracy of EGC depth.

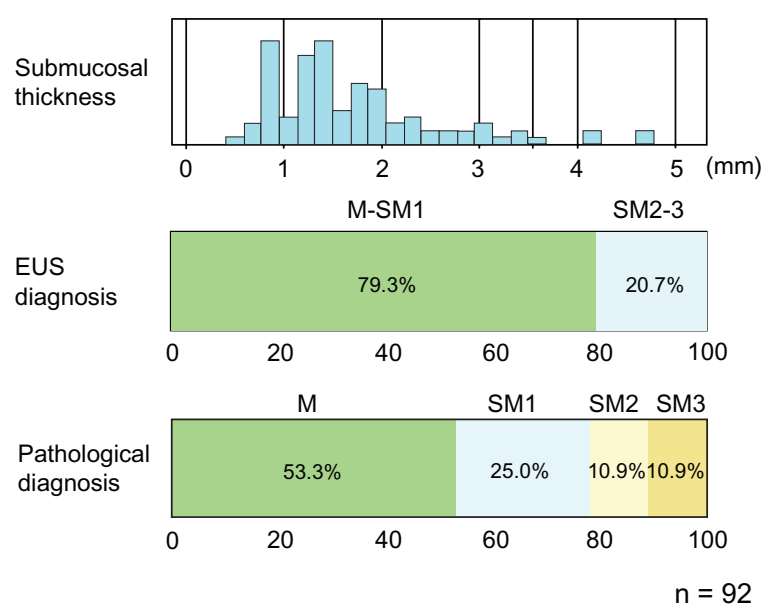

Figure 4 Bar graph showing the distribution of submucosal thickness. The corresponding diagnoses of mucosal-submucosal (M-SM) I and submucosal (SM) 2/3 cancer based on endoscopic ultrasonography, and mucosal (M), SMI, SM2, and SM3 cancer based on pathological results are shown. Before the treatment, $73(79.3 \%)$ of the early gastric cancers (EGCs) were diagnosed as M-SMI cancer and 19 (20.7\%) as SM2/3 cancer but, based on pathological examinations, $49(53.3 \%)$ of these EGCs were diagnosed as M cancer, 22 (25.0\%) as SMI cancer, ten (10.9\%) as SM2 cancer, and eleven (10.9\%) as SM3 cancer.

Abbreviation: EUS, endoscopic ultrasonography.
No differences between the submucosal thickness of lesions associated with M and SM1 cancers were observed. This observation indicates that slight invasion into the submucosal layer, as observed in SM1 cancers, is a low-risk indicator for lymph node metastasis and causes only minor inflammatory reactions, and therefore does not affect the thickness of the submucosal layers. However, if the submucosal invasion exceeds $500 \mu \mathrm{m}$, protective and major inflammatory reactions are initiated, increasing the risk of

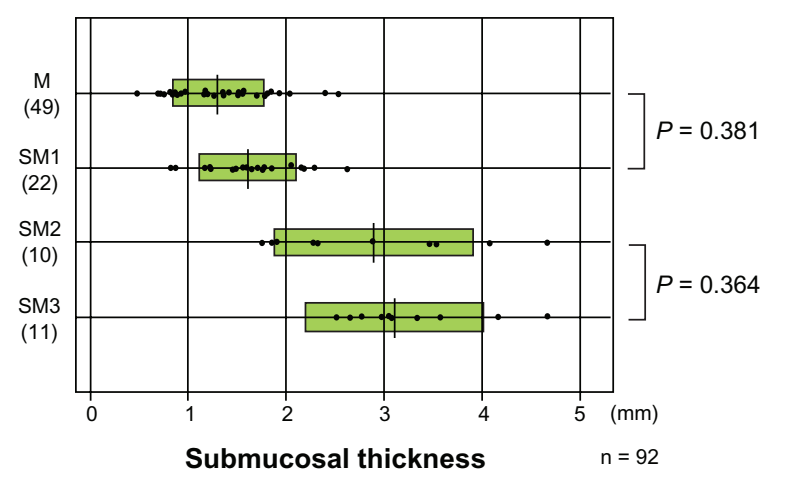

Figure $\mathbf{5}$ Scatter plot showing the distribution of submucosal thickness values according to the type of cancer (mucosal-submucosal [M-SM] I, submucosal [SM] 2, and SM3). Note: As seen from the plot, there was no significant difference in submucosal thickness between the mucosal $(M)$ and SMI cancer $(P=0.38 \mathrm{I})$, and also between the SM2 and SM3 cancers $(P=0.364)$. 


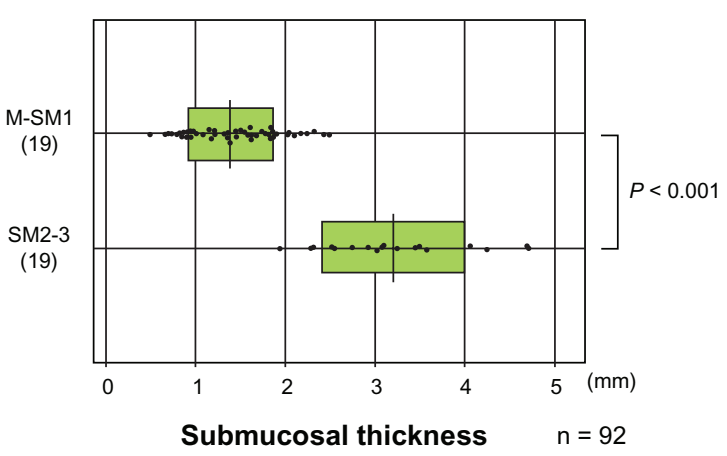

Figure 6 Scatter plot showing submucosal thickness according to the endoscopic ultrasonography diagnosis of mucosal-submucosal (M-SM) I and SM2/3 cancers.

Note: $A$ significant difference in submucosal thickness was found between the two types of cancers $(P<0.00 \mathrm{I})$.

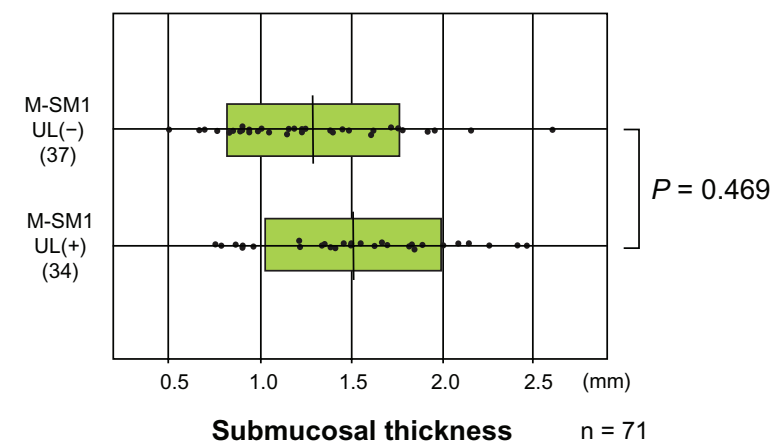

Figure 7 Scatter plot showing distribution of submucosal thickness for mucosalsubmucosal (M-SM)I cancers according to the presence $(+)$ or absence $(-)$ of ulceration.

Note: No significant difference was found between these groups of M-SMI cancers $(P=0.469)$. lymph node metastasis. ${ }^{1}$ This inflammation, accompanied by a cancerous mass, leads to an increase in the thickness of the submucosal layer, which is reflected in the significant differences between submucosal thickness in M-SM1 and SM2/3 cancers.

The authors believe it is important to consider the possibility of fibrosis, as ulceration influences changes in submucosal thickness. As shown in Table 2, which shows the presence or absence of ulceration and the depth of invasion and localization in the stomach, no significant differences were found in the localization of the lesions. Moreover, when the M-SM1 cancers were subdivided into the UL(-) and UL(+) groups and the differences between submucosal thickness in each group were examined, no significant differences were found between the groups. It was not possible to perform the same comparison for the SM2/3 cancers because only two cases had been classified as UL(-) (Figure 7). Based on these results, it was concluded that the fibrosis accompanying ulceration is not the main factor responsible for the increased thickness of the submucosal layer (Figure 3c); rather, inflammatory cell infiltration and the cancer itself are the main factors. This conclusion is supported by the authors' finding that the submucosal layer was thickest in SM3 cancers, followed by SM2 and then SM1 cancers (Figure 5).

By comparing the thickness of the submucosal layers as measured by EUS and the pathological depth as diagnosed by a pathological examination, a cut-off threshold of $2.2 \mathrm{~mm}$

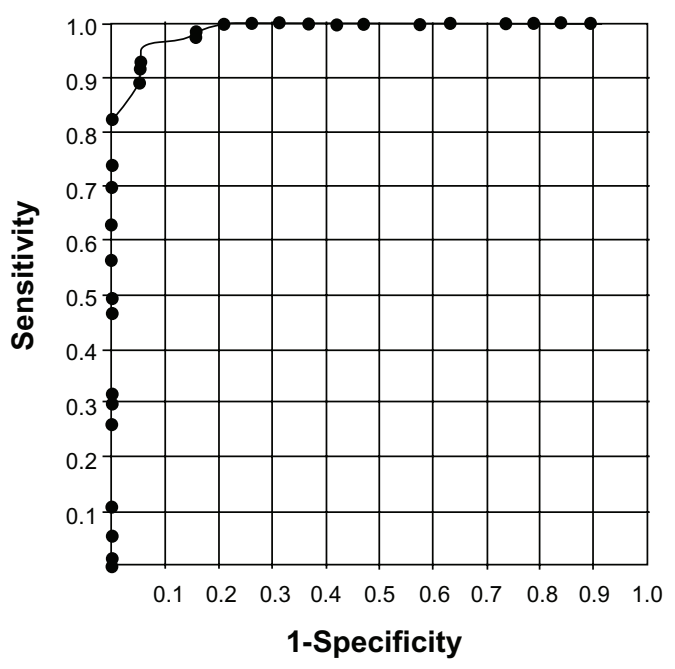

Area under the curve $=0.988$
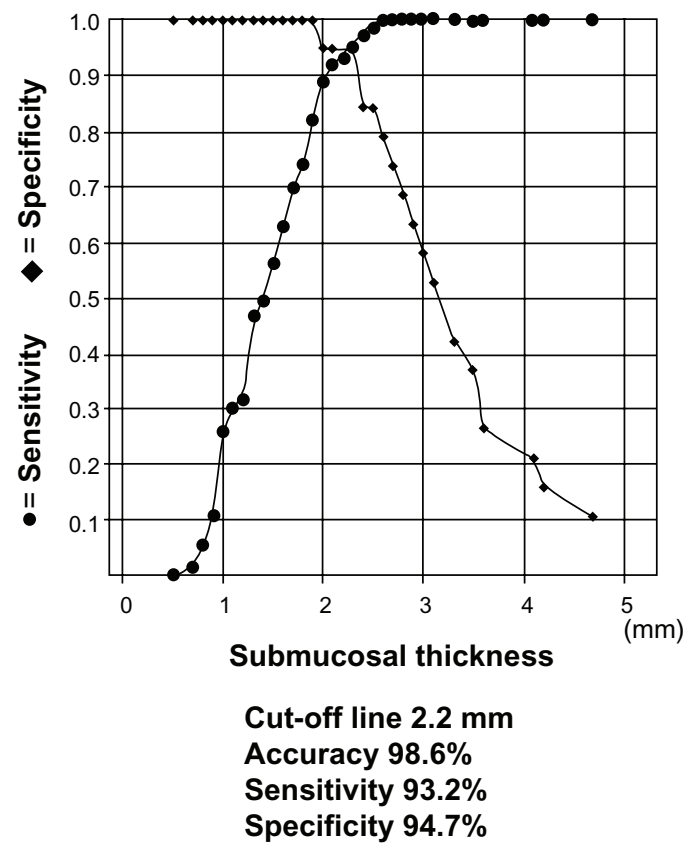

Figure 8 Receiver operating characteristic curve of the submucosal thickness values to determine the cut-off value for distinguishing between mucosal-submucosal (M-SM) I and SM2/3 cancers, and the sensitivity, specificity, and accuracy of using this cut-off value. For the cut-off value of $2.2 \mathrm{~mm}$, the accuracy, sensitivity, and specificity were $98.6 \%, 93.2 \%$, and $94.7 \%$, respectively. 
was identified for submucosal thickness in the differentiation between M-SM1 and SM2/3 cancers. Using this threshold, the 2 types of cancer could be differentiated with $98.6 \%$ accuracy, 93.2\% sensitivity, and $94.7 \%$ specificity. However, a major measurement limitation was the fact that four patients $(4.1 \%)$ presented with submucosal cysts. As the cysts themselves may have been responsible for any increased thickness of the submucosal layer, the authors' method could not be used to measure the depth of the lesion in these patients. Therefore, it is necessary to identify cysts in the submucosal layer before measuring the submucosal thickness.

\section{Conclusion}

By measuring the thickness of the submucosal layers of EGC by EUS, it is possible to successfully distinguish M-SM1 from SM2/3 cancers in a precise manner for more accurate differential diagnosis than by review of EUS measurements alone. Use of this method allows for accurate diagnosis even in cases presenting with undifferentiated types of cancer or with ulceration, in which the deepest area of cancer invasion is difficult to determine.

\section{Disclosure}

The authors report no conflicts of interest in this work.

\section{References}

1. Gotoda T, Yanagisawa A, Sasako M, et al. Incidence of lymph node metastasis from early gastric cancer: estimation with a large number of cases at two large centers. Gastric Cancer. 2000;3:219-225.

2. Mitsunaga A, Shirato I, Nishino T, et al. Diagnosis of SM1 differentiated type early gastric cancer (penetrates into the submucosa less than $500 \mu \mathrm{m}$ ) compared with SM2 early gastric cancer (penetrates into the submucosa over $500 \mu \mathrm{m}$ ): endoscopic diagnosis of depressed type early gastric cancer with converging folds [ひだ集中のある陷型早期胃癌における内 視鏡診断]. Stomach and Intestine (Tokyo) 2007;42:61-68. Japanese.

3. Japanese Gastric Cancer Association. Gastric Cancer Treatment Guidelines. 2nd edition. Kyoto: Kanehara; 2004. Japanese.
4. Yanai H, Matsumoto Y, Harada T, et al. Endoscopic ultrasonography and endoscopy for staging of depth of invasion in early gastric cancer: a pilot study. Gastrointest Endosc. 1997;46:212-216.

5. Yanai H, Noguchi T, Mizumachi S, et al. A blind comparison of the effectiveness of endoscopic ultrasonography and endoscopy in staging early gastric cancer. Gut. 1999;44:361-365.

6. Yoshida S, Tanaka S, Kunihiro K, et al. Diagnostic ability of high-frequency ultrasound probe sonography in staging early gastric cancer, especially for submucosal invasion. Abdom Imaging. 2005;30: 518-523.

7. Yanai H, Matsubara Y, Kawano T, et al. Clinical impact of strip biopsy for early gastric cancer. Gastrointest Endosc. 2004;60:771-777.

8. Ohashi S, Segawa K, Okamura S, et al. The utility of endoscopic ultrasonography and endoscopy in the endoscopic mucosal resection of early gastric cancer. Gut. 1999;45:599-604.

9. Chonan A. Clinical evaluation of endoscopic ultrasonography (EUS) in the diagnosis of depressed type early gastric cancer [陥凹型早期胃癌 における超音波内視鏡(EUS)深達度診断能の検討]. Gastroenterol Endosc. 1993;35:1269-1281. Japanese.

10. Akashi K, Yanai H, Nashikawa J, et al. Ulcerous change decreases the accuracy of endoscopic ultrasonography diagnosis for the invasive depth of early gastric cancer. Int J Gastrointest Canc. 2006;37:133-138.

11. Yasuda K. Development and clinical use of ultrasonic probes. Endoscopy. 1994;26:816-817.

12. Chonan A, Mishima T, Miyake N, et al. Endoscopic ultrasonographic diagnosis of depth of invasion of early gastric cancer [超音波内視 鏡による早期胃癌の深達度診断]. Stomach and Intestine (Tokyo). 2009;44(4):623-635. Japanese.

13. Matsumoto Y, Yanai H, Tokiyama H, Nishiaki M, Higaki S, Okita K. Endoscopic ultrasonography for diagnosis of submucosal invasion in early gastric cancer. J Gastroenterol. 2000;35:326-331.

14. Tsendsuren T, Jun SM, Mian XH. Usefulness of endoscopic ultrasonography in preoperative TNM staging of gastric cancer. World J Gastroenterol. 2006;12:43-47.

15. Isobe S, Yoshino J, Inui K, et al. Endosonographic diagnosis of the depth of cancerous invasion of differentiated type gastric cancer [超音 波内視鏡検査による胃分化型SM1癌の深達度診断]. Stomach and Intestine (Tokyo). 2007;42(1):79-87. Japanese.

16. Bentrem D, Gerdes H, Tang L, Brennan M, Coit D. Clinical correlation of endoscopic ultrasonography with pathologic stage and outcome in patients undergoing curative resection for gastric cancer. Ann Surg Oncol. 2007; 14:1853-1859.

17. Mouri R, Yoshida S, Tanaka S, Oka S, Yoshihara M, Chayama K. Usefulness of endoscopic ultrasonography in determining the depth of invasion and indication for endoscopic treatment of early gastric cancer. J Clin Gastroenterol. 2009;43:318-322.

18. Kim JH, Song KS, Youn YH, et al. Clinicopathologic factors influence accurate endosonographic assessment for early gastric cancer. Gastrointest Endosc. 2007;66:901-908.
Gastrointestinal Cancer: Targets and Therapy

\section{Publish your work in this journal}

Gastrointestinal Cancer: Targets and Therapy is an international, peer-reviewed, open access journal focusing on gastro-intestinal cancer research, identification of therapeutic targets and the optimal use of preventative and integrated treatment interventions to achieve improved outcomes, enhanced survival and quality of life for the
Dovepress

cancer patient. The manuscript management system is completely online and includes a very quick and fair peer-review system. Visit http://www.dovepress.com/testimonials.php to read real quotes from published authors. 